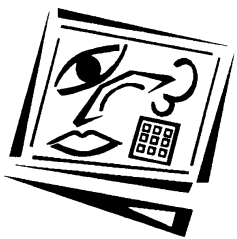

\title{
Why don't all maths teachers use dynamic geometry software in their classrooms?
}

\author{
Gerrit Stols \\ University of Pretoria \\ Jeanne Kriek \\ University of South Africa
}

\begin{abstract}
In this exploratory study, we sought to examine the influence of mathematics teachers' beliefs on their intended and actual usage of dynamic mathematics software in their classrooms. The theory of planned behaviour (TPB), the technology acceptance model (TAM) and the innovation diffusion theory (IDT) were used to examine the influence of teachers' attitudes, subjective norms and perceived behavioural control on their intention to use dynamic mathematics software in their classrooms. The study adopted the co-relational research design, with both correlation statistics and regression analysis used to analyse the data. By using stepwise regression analysis, it was possible to identify the most important belief predictors and their weights for the different constructs. The results were verified by the use of partial least squares. This study found that beliefs about the perceived usefulness and beliefs about their level of technological proficiency are the most important predictors of teachers' intended and actual usage of the software. In this preliminary study the suggested simplified model sufficiently explains $15(83.3 \%)$ of the 18 teachers adaption and use of dynamic mathematics software in their classrooms.
\end{abstract}

\section{Introduction}

Researchers agree that technology can be used effectively as a cognitive tool for teaching and learning in the classroom (Bruce \& Levin 2001; Bransford, Brown \& Cocking 2000). Technology has the potential to enhance instruction, with respect to mathematics teaching in particular (Connell, 1998; Roschelle, Pea, Hoadley, Gordin \& Means 2000). In fact, Dede (2000) indicates that technology can be used to strengthen student learning and enhance pedagogy. Dynamic mathematics software such as GeoGebra, Cabri, and Geometer's Sketchpad was originally designed for teaching geometry in secondary schools. This software allows learners to discover patterns, to explore and to test conjectures by constructing their own sketches. Dynamic mathematics software is a powerful teaching and learning medium and it has been reported to (a) enhance mathematics teaching; (b) help with conceptual development; (c) enrich visualisation of geometry; (d) lay a foundation for analysis and deductive proof; and (e) create opportunities for creative thinking (Sanders 1998). School students can improve their understanding using software because the dynamic environment improves visualisation skills and ability to focus on interrelationships of the parts of geometric shapes (Clements, Sarama, Yelland \& Glass, 2008). 
However, even if technology is available, it is rarely used for teaching mathematics (Vrasidas \& Glass, 2005; Marcinkiewicz, 1994). The question is: if dynamic mathematics software is such a powerful teaching and learning tool, why don't all teachers use it in their classrooms?

Cuban (2001) warns that explaining teachers' behaviour in using or not using technology needs to go beyond popular explanations that tend to blame teachers. Research explains how and why individuals adopt new information technologies (Venkatesh, Morris, Davis \& Davis, 2003), but it is not known what influences teachers to use technology in their classroom. This study focuses on the use of dynamic mathematics software by teachers in their mathematics classrooms. To understand teachers' use of technology in their classrooms, we need a better understanding of the beliefs that influence teachers to decide to use technology or not to use it. Hew and Brush (2007), Albion (2001), and Teo (2008) have identified teachers' attitudes and beliefs as barriers to using technology for instruction. Social influence which is about the beliefs of what other people believe also has a direct influence on intention to use technology (Debuse, Lawley \& Shibl, 2008).

Problems can emerge when teachers' beliefs are ignored, because "beliefs and values that teachers hold drive many of the choices they make in the classroom" (Cuban, 2001, p. 169). Cuban (2001) argues that beliefs influence what and how teachers choose to teach and what innovations they endorse or reject. In addition, "teachers' beliefs and principles are contextually significant to the implementation of innovations" (Munby, 1984, p. 28). We therefore need a deeper understanding of the nature of beliefs that influence the behaviour of a teacher and how these beliefs are manifested. With this in mind, we introduced dynamic mathematics software (GeoGebra, Cabri, Geometer's Sketchpad) to mathematics teachers in a preliminary study to investigate whether they would use it in teaching mathematics, and which reasons may prevent them from implementing the program.

\section{Theoretical framework}

Various models exist for trying to predict and explain human behaviour. In 1975 Icek Ajzen and Martin Fishbein developed a model that explains the relationship between beliefs and behaviour. In brief, the theory of reasoned action (TRA) explains that behaviour is driven by behavioural intentions, while behavioural intentions are driven by attitude and subjective norms.

\section{Theory of planned behaviour (TPB)}

Ajzen realised that all behaviour is not under volitional control, and in 1988 included perceived behavioural control as one of the three main factors that drive behavioural intention. This extension of the TRA is called the theory of planned behaviour (TPB). The TPB explains human action and suggests that human action is guided by behavioural beliefs (BB), normative beliefs (NB), and control beliefs (CB) (see Figure 1).

Together, these three factors will determine the behavioural intention, and hence in the end also the behaviour, given sufficient degree of actual control over the behaviour. Ajzen (1991) explains that behavioural beliefs (BB) are beliefs about the probable outcomes of behaviour and the corresponding judgements about these outcomes, while normative beliefs (NB) are about the expectations of other people and motivation to comply with their expectations. 


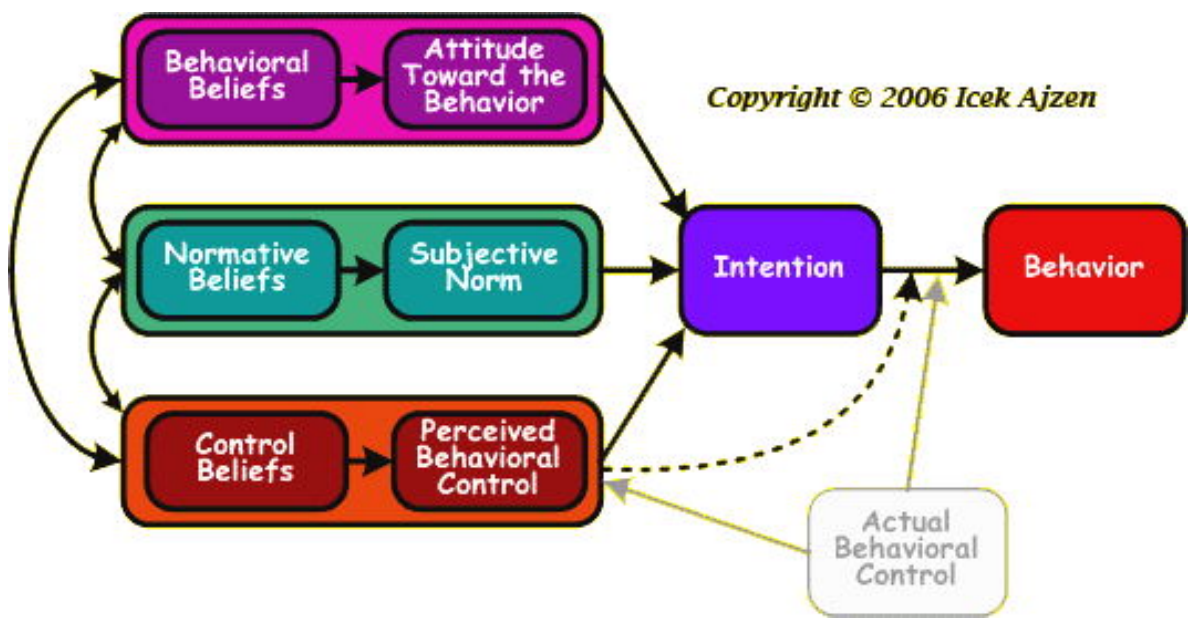

Figure 1: Theory of planned behaviour (TPB) (Ajzen, 2006)

Control beliefs (CB) include beliefs about both internal and external factors that may facilitate or impede performance of behaviour. Internal factors include skills, abilities and emotions, while external factors include environmental factors such as beliefs about infrastructure, support staff and access to computers.

The TBP explains human behaviour in general settings. To elucidate and explain behavioural beliefs (BB) in the context of information technology, various models about the adoption of technology innovations were investigated. Information technology researchers have developed various models for studying the software utilisation choices of users; for example the technology acceptance model (TAM) and the theory of innovation diffusion (IDT). These models can also be used to clarify and explain behavioural beliefs in the context of the use of technology for instruction (Thang, Murugaiah, Lee, Hazita Azman, Tan \& Lee, 2010).

\section{Technology acceptance model (TAM)}

In 1992 Davis and Bagozzi adapted the TRA to develop the technology acceptance model (TAM), as an attempt to explain factors that influence users' acceptance of information technology systems. TAM currently enjoys the status of being the prime tool for testing user acceptance of new technologies (Rivera Green, 2005).

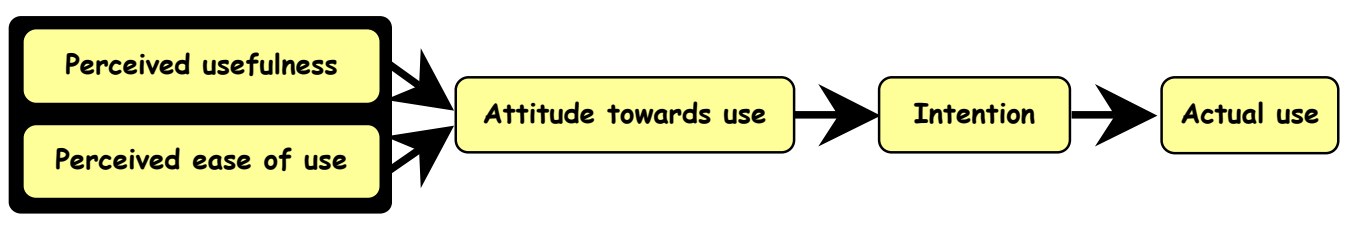

Figure 2: Technology acceptance model (TAM)

This model ignores the role of normative beliefs (see the TRA), and replaces behavioural beliefs about the outcome with only two beliefs - perceived ease of use (PEOU) and perceived usefulness (PU) (see Figure 2). Although this model is much 
simpler than the TPB, it matches up quite favourably in the IT context (Venkatesh \& Davis, 2000). Perceived usefulness is about the extent "to which a person believes that using the system will enhance his or her job performance", while perceived ease of use is about "a person's beliefs that using the specific technology will be free of effort" (Davis, 1989, p. 320). Several researchers have replicated Davis's research and found perceived usefulness to be a strong determinant of user intentions (Venkatesh \& Davis, 2000, p. 186):

\begin{abstract}
Numerous empirical studies have found that TAM consistently explains a substantial proportion of the variance (typically about $40 \%$ ) in usage intentions and behavior... In 10 years, TAM has become well-established as a robust, powerful, and parsimonious model for predicting user acceptance.
\end{abstract}

Sheppard, Hartwick and Warsaw (1988) found a correlation coefficient $(r)$ of 0.54 between behaviour intention and actual use within the field of consumer behaviour. Currently TAM is a well-established model and is widely accepted among researchers in the field of IT.

\title{
Theory of innovation diffusion (IDT)
}

Rogers (2003) used the theory of innovation diffusion (IDT) to study a variety of innovations. This model explains that the five key elements that determine the acceptance and use of innovations are relative advantage, complexity of the innovation, compatibility, trialability, and observability. According to Moore and Benbasat (1991, p. 195), relative advantage is about "the degree to which an innovation is perceived as being better than its precursor", while complexity is "the degree to which an innovation is perceived as being difficult to use" (p. 195). Compatibility refers to "the degree to which an innovation is perceived as being consistent with the existing values, needs, and past experiences of potential adopters". This component has been added. For this study trialability, which is about availability, has been addressed by the TPB's control beliefs, and because of the nature of teaching with dynamic geometry software, observability has been included in relative advantage.

\section{Combination of TBP, TAM and IDT}

A close similarity exists between the variables in the TAM and IDT models: the relative advantage of the innovation in IDT is related to the perceived usefulness (PU) in TAM, while the complexity of the innovation of IDT is related to the perceived ease of use (PEOU) of TAM. Perceived compatibility (PC) has been added from IDT and therefore in the Combined Model attitudes are postulated to be influenced by PU, PEOU and PC.

The subjective norm (SN) in the TBP is "the person's perception that most people who are important to him think he should or should not perform the behaviour in question" (Fishbein \& Ajzen 1975, p. 302). In a teaching context, the people who could influence teachers' normative beliefs are typically the principal, learners, parents, and colleagues.

Perceived behaviour control (PBC) is influenced by individuals' control beliefs. According to McCabe (2004, p. 503), control beliefs are a function of both external and internal control beliefs: "Thus intention to behave is a function of perceived internal control (i.e. confidence in skills and abilities) and behaviour is a function of external control (i.e. opportunity and resources available)". In the case of this study, the internal 
control beliefs are about the teachers' general technology proficiency (GTP), while the external control beliefs are about the availability of the IT infrastructure (ITI).

Combining the TPB, TAM and IDT results in a new model (see Figure 3) which will be referred to as the Combined Model and has the potential to improve our understanding of technology use by teachers in general, and also in their classroom for instruction. This Combined Model will be used as a framework for analysing the reflections.

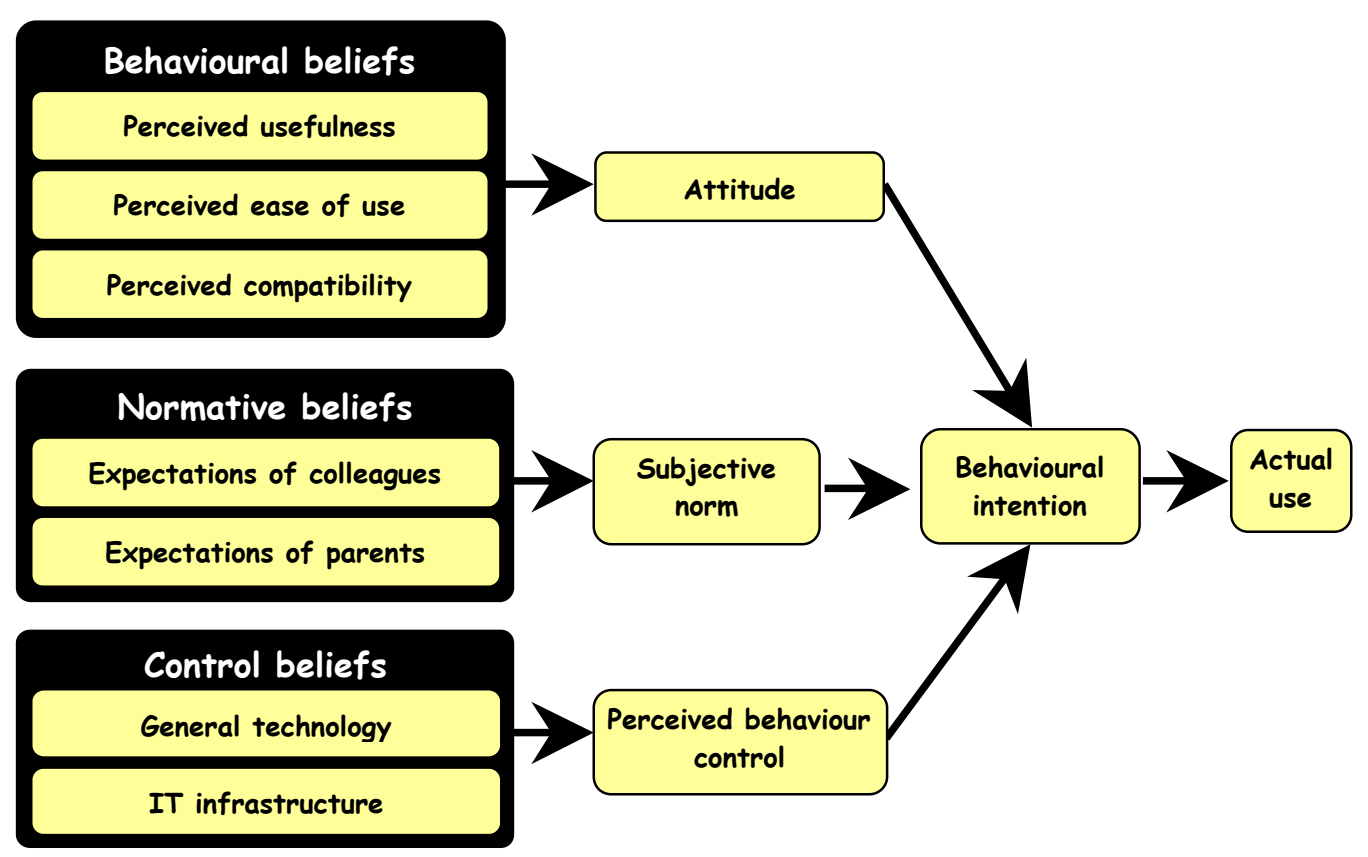

Figure 3: The Combined Model

\section{Research aim}

The aim of this research was threefold. The first was to examine the influence of grade 10 to 12 (16-18 years) mathematics teachers' behavioural beliefs, normative beliefs and control beliefs on their attitudes, subjective norm, and perceived behaviour control respectively. The second objective of the study was to determine the impact of teachers' attitudes, subjective norm, and perceived behaviour control on their intention of using dynamic geometry software in their classrooms to develop concepts in the context of transformations, functions, or geometry. Finally, their actual usage was compared with their intention to use dynamic geometry software.

\section{Research design}

The exploratory study adopted the co-relational research design. This design finds the statistical relationship between two or more variables. Both correlation statistics and regression analysis were used to analyse the data. The correlation statistics were used to find the correlation between the beliefs and their respective direct measures of the constructs in Figure 3. For example, correlation was found between the beliefs about 
usefulness, ease of use, and compatibility of using dynamic geometry software with the attitude towards the use of the software. By using stepwise regression analysis and finding the values of $r$ squared, it was possible to identify the weights of the attitudes, subjective norm, and perceived behaviour control on the intention to use dynamitic geometry software. The intention was then compared with the actual usage by using descriptive statistics. This is a small scale exploratory study with a small sample size. This imposed some limitations in terms of generalisability of results. This is why this study also employed a structural equation modelling technique, in this case confirmatory factor analysis from partial least squares, as a way to triangulate findings derived from the correlation and regression analysis.

\section{Participants and procedure}

The study was done in South Africa using two convenience samples of teachers. The first sample consisted of 12 high school teachers from seven different schools in semiurban areas, while the second sample consisted of 12 high school teachers from eight different urban schools. Data was obtained from only 22 (12 male and 10 female) teachers, who represented a variety of cultures. The average teaching experience of the 22 teachers was 18 years and their average age 45.5 years. Three deputy principals, seven heads of mathematics departments and twelve teachers attended the workshops. Fifteen of the teachers did have ICT skills and ten were using ICT - not necessarily for teaching but in compiling question papers and marks. Follow up interviews were conducted with the teachers three months after the workshops.

\section{Questionnaire}

The questionaire was designed by the authors using the guidelines set by Francis et al (2004) in the document: Constructing questionnaires based on the Theory of Planned Behaviour. The first step in the design of the instrument was to conduct an elicitation study to elicit commonly held beliefs about the use of technology. In order to to identify possible salient beliefs of teachers regarding the use of educational software we reviewed 53 publications that were selected for their relevance. From the publications, we clustered factors influencing attitude, subjective norm and perceived behaviour control. In the case of attitudes, the following salient beliefs were identified: pedagogical compatibility of the technology, perceived ease of use of the technology and its perceived usefulness. The beliefs influencing subjective norm were normative beliefs about colleagues, learners, the principal and parents. Finally, perceived behaviour control was influenced by internal control beliefs such as belief in one's own general technology proficiency and software skills, while external control beliefs referred to such aspects as infrastructure, IT support staff and access to technology or an IT lab. The questionnaire consisted of 132 questions. The following is an example of a question in the questionnaire to determine behaviour belief perceived usefulness (BBPU): "The use of dynamic geometry software will make it easier for the learners to visualise the transformation of functions". A 7-point Likert scale was used for all the questions, varying from "extremely unlikely" to "extremely likely", or "definitely false" to "definitely true".

\section{Workshop}

Teachers must know and understand the advantages, limitations, functions and complexity of a software package to be able to form an opinion. Therefore, the first author conducted a three-hour workshop one day a week for three consecutive weeks 
on the use of dynamic geometry software in the mathematics classroom before the teachers completed the questionnaire to investigate their beliefs. The workshop covered geometric transformations (a new topic in the South African curriculum that uses hands on activities), transformations of graphs of functions, and Euclidian geometry. In essence, the workshop integrated the development of computer skills and mathematical discovery. In developing mathematics activities and materials, we followed the guidelines of (a) addressing worthwhile mathematics with appropriate pedagogy; (b) taking advantage of technology; (c) connecting mathematics topics; and (d) incorporating multiple representations (Garofalo, Drier, Harper, Timmerman \& Shockey, 2000).

\section{Results}

Correlation statistics and regression analyses were used to analyse the data. Correlation statistics were used to find the correlation between the different behavioural beliefs (BB) while regression analysis was used to identify the weights of the attitude (A), subjective norm (SN) and perceived behaviour control (PBC) on the intention to use dynamic geometry software. This was also confirmed by factor analyses from partial least squares. In the following correlations, ** indicates a significance at the 0.01 level (two-tailed) and * a significance at the 0.05 level (twotailed). The most important predictors and their weights were identified by using stepwise regression analysis. Table 1 presents a summary of the responses in the questionnaire about the different categories and constructs of the Combined Model. Each category will be discussed.

Table 1: Summary of the responses in the questionnaire about the different constructs of the TPB (7-point Likert scale was used.)

\begin{tabular}{|c|c|c|c|c|c|}
\hline & $\mathrm{N}$ & Minimum & Maximum & Mean & $\begin{array}{l}\text { Standard } \\
\text { deviation }\end{array}$ \\
\hline Behaviour intention & 20 & 1.67 & 7.00 & 5.5833 & 1.73332 \\
\hline Attitude & 22 & 5.00 & 7.00 & 6.5114 & 0.66134 \\
\hline Pedagogical compatibility & 23 & 4.00 & 7.00 & 5.8261 & 1.00689 \\
\hline Perceived ease of use & 23 & 3.29 & 6.43 & 4.3602 & 0.70496 \\
\hline Perceived usefulness & 22 & 4.86 & 7.00 & 6.3214 & 0.60799 \\
\hline Subjective norm & 23 & 4.50 & 7.00 & 6.1739 & 0.77765 \\
\hline \begin{tabular}{|l|l} 
& Normative beliefs (colleagues)
\end{tabular} & 23 & 3.50 & 7.00 & 5.5833 & 1.00722 \\
\hline Normative beliefs (parents) & 23 & 2.50 & 7.00 & 4.9167 & 1.42697 \\
\hline Control beliefs & 21 & 2.90 & 6.90 & 5.1333 & 1.03795 \\
\hline \begin{tabular}{l|l} 
General technology proficiency
\end{tabular} & 23 & 1.20 & 5.50 & 3.6435 & 1.17892 \\
\hline IT Infrastructure & 20 & 2.00 & 7.00 & 4.9333 & 1.94245 \\
\hline
\end{tabular}

\section{Influence of behavioural beliefs (BB) on attitude (A)}

According to the Combined Model, behavioural beliefs will produce a positive or negative attitude towards the behaviour. Behavioural beliefs include beliefs about the perceived usefulness (PU), perceived ease of use (PEOU), and perceived compatibility (PC) of dynamic geometry software.

The highly significant correlation of 0.902 between the perceived usefulness (PU) and perceived compatibility (PC) of using dynamic geometry software for teaching indicates that these teachers think about the usefulness of dynamic geometry software in terms of the pedagogical compatibility (see Table 2). Ertmer (2005, p. 36) argues that 
"if we truly hope to increase teachers' uses of technology, especially uses that increase student learning, we must consider how teachers' current classroom practices are rooted in, and mediated by, existing pedagogical beliefs". Zhao and Cziko (2001, p. 17) use the perceptual control theory (PCT) to explain this phenomenon in terms of a hierarchy: "Since technology use is at a lower level of the hierarchy than pedagogical beliefs and teaching approaches, and because lower level goals are easier to vary, it is no surprise that many teachers adopt technology without changing their pedagogy."

Table 2: Summary of the Pearson correlation coefficients between behavioural beliefs (BB) and attitude (A) with $\mathrm{N}=22$

\begin{tabular}{|l|c|}
\hline & A \\
\hline Perceived usefulness (PU) & $0.889\left(^{* *}\right)$ \\
\hline Perceived ease of use (PEOU) & -0.137 \\
\hline Pedagogical compatibility (PC) & $0.816\left(^{\star *}\right)$ \\
\hline
\end{tabular}

Table 3: Summary of the regression analysis for attitude (A)

\begin{tabular}{|c|c|c|c|c|c|}
\hline Predictor & $\mathrm{r}$ & r square & $\mathrm{F}$ & Sig. & $\mathrm{df}$ \\
\hline Perceived usefulness (PU) & 0.885 & 0.784 & 65.300 & 0.000 & 1 \\
\hline Predictor & B & Std error & Beta & $\mathrm{t}$ & Sig. \\
\hline Perceived usefulness (PU) & 0.972 & 0.120 & 0.885 & 8.081 & 0.000 \\
\hline
\end{tabular}

From the regression analyses, however, it emerged that the most significant predictor of attitude towards the use of dynamic geometry software is its perceived usefulness (PU) (see Table 3). The implication is that the perceived compatibility (PC) does not directly determine the attitude but rather works through the perceived usefulness (PU) to influence the attitude. The perceived ease of use (PEOU) of dynamic geometry software had a negative but insignificant influence on the attitude towards its use.

Partial least squares were used to determine the reliability of the above results. The model effect loadings for prediction of PU, PEOU and PC on attitudes were 0.610, 0.128 and 0.621 respectively, with weights of $0.664,-0.086$ and 0.608 . It can be concluded that only beliefs about PU and PC influence attitudes and therefore this result is highly consistent with the results from the regression analyses and correlation statistics.

\section{Influence of normative beliefs (NB) on subjective norm (SN)}

Normative beliefs (NB) refer to the perceived behavioural expectations of important individuals, leaders, groups or colleagues. Judging from the literature in a teaching context, these would typically be colleagues, learners, parents and the principal. The theory of planned behaviour assumes that these normative beliefs, in combination with the person's motivation to comply with them, determine the subjective norm (SN).

Table 4: Summary of the Pearson correlation coefficients between normative beliefs (NB) and subjective norm (SN) with $\mathrm{N}=22$

\begin{tabular}{|l|c|}
\hline & SN \\
\hline NB (colleagues) & $0.363\left(^{*}\right)$ \\
\hline NB (parents) & -0.017 \\
\hline
\end{tabular}


The correlation coefficient of 0.363 between subjective norm and normative beliefs (colleagues) is significant at the 0.10 level only.

Table 5: Summary of the regression analysis for subjective norm (SN)

\begin{tabular}{|l|c|c|c|c|c|}
\hline Predictor & r & r square & F & Sig. & df \\
\hline Colleagues & 0.363 & 0.132 & 3.196 & 0.088 & 1 \\
\hline Predictor & B & Std error & Beta & t & Sig. \\
\hline Colleagues & 0.274 & 0.154 & 0.363 & 1.788 & 0.088 \\
\hline
\end{tabular}

From Tables 4 and 5 it is clear that the expectations of the parents or colleagues did not have any significant impact on the subjective norm of these teachers. This nonsignificant impact was also confirmed by the factor analysis of partial least squares. This is understandable, because in a normal schooling context teachers have the authority to make their own decisions in the classroom. They act relatively independently within their classrooms and have considerable autonomy over their teaching activities $(\mathrm{Hu}, \mathrm{Clark} \& \mathrm{Ma}, 2003)$. The pressure from peers or colleagues to use technology for instruction is therefore limited.

\section{Influence of control beliefs (CB) on perceived behavioural control (PBC)}

Perceived behavioural control is about the presence of factors that may facilitate or impede performance of the behaviour, and the perceived power of these factors (Ajzen, 1991). In the context of this article, perceived behavioural control relates to factors influencing the extent to which teachers feel able to use dynamic geometry software in the classroom. Control beliefs include both internal and external factors. Internal control beliefs include the teacher's perception of his or her general technology proficiency (GTP), while the external control beliefs are about the availability of the IT infrastructure (ITI).

Table 6: Summary of the Pearson correlation coefficients between control beliefs (CB) and perceived behavioural control (PBC) with $\mathrm{N}=22$

\begin{tabular}{|l|c|}
\hline & PBC \\
\hline GTP & $0.754\left(^{* *}\right)$ \\
\hline ITI & $0.498\left(^{*}\right)$ \\
\hline
\end{tabular}

Table 7: Summary of the regression analysis for perceived behavioural control (PBC)

\begin{tabular}{|l|c|c|c|c|c|}
\hline Predictor & r & r square & F & Sig. & df \\
\hline GTP & 0.754 & 0.568 & 22.391 & 0.000 & 1 \\
\hline Predictor & B & Std error & Beta & t & Sig. \\
\hline GTP & 1.160 & 0.245 & 0.754 & 4.732 & 0.000 \\
\hline
\end{tabular}

Both the general technology proficiency (GTP) of the teacher and the availability of IT infrastructure (ITI) relate to the perceived behavioural control (PBC). A strong positive, statistically significant correlation of 0.754 was found between perceived behavioural control (PBC) and the general technology proficiency (GTP) of the teachers. A weaker but significant correlation of 0.498 exists between perceived behavioural control (PBC) and the IT infrastructure (ITI). Table 7 shows that the general technology proficiency (GTP) of a teacher explains $56.8 \%$ of his or her perceived behavioural control (PBC). 
The partial least squares model effect loadings for GTP and ITI on PBC were 0.647 and 0.530 respectively, with effect weights of 0.714 and 0.471 . The regression and partial correlation results suggest that GTP and ITI mediate the effect of PBC.

\section{Influence of attitude (A), subjective norm (SN) and perceived behavioural control (PBC) on behaviour intention (BI)}

According to Tables 8 and 9, a positive, statistically significant correlation was found between behavioural intention (BI) and both the attitude (A) and the perceived behavioural control (PBC). However, from the regression analyses it emerged that the most significant predictor of behavioural intention (BI) is perceived behavioural control (PBC).

Table 8: Summary of the Pearson correlation coefficients between attitude (A), subjective norm (SN), control beliefs $(\mathrm{CB})$ and behavioural intention $(\mathrm{BI})$ with $\mathrm{N}=22$

\begin{tabular}{|l|c|}
\hline & BI \\
\hline A & $0.551\left(^{*}\right)$ \\
\hline SN & 0.233 \\
\hline PBC & $0.677\left(^{* *}\right)$ \\
\hline
\end{tabular}

Table 9: Summary of the regression analysis for behavioural intention (BI)

\begin{tabular}{|c|c|c|c|c|c|}
\hline Predictor & $\mathrm{r}$ & r square & $\mathrm{F}$ & Sig. & $\mathrm{df}$ \\
\hline PBC & 0.671 & 0.451 & 13.942 & 0.002 & 1 \\
\hline Predictor & B & Std error & Beta & $t$ & Sig. \\
\hline PBC & 0.597 & 0.160 & 0.671 & 3.734 & 0.002 \\
\hline
\end{tabular}

The partial least squares model effect loadings for $\mathrm{A}, \mathrm{SN}$, and $\mathrm{PBC}$ on $\mathrm{BI}$ were 0.448 , 0.214 , and 0.502 , with effect weights of $0.464,0.206$, and 0.577 respectively. The regression and partial correlation results suggest that $\mathrm{A}$ and $\mathrm{PBC}$ influence $\mathrm{BI}$ and that SN does not contribute to BI.

\section{Actual use in the classroom}

According to the Combined Model, the actual usage of dynamic geometry software will be influenced by the BI. Therefore we compared the average score of the six questions in the questionnaire that were posed to determine the BI and compare it with the teacher's actual use of dynamic geometry software in his or her classrooms. Using the average score for these questions regarding behavioural intention, we regarded a score of higher than 4 on the 7-point Likert scale as positive indication of their intention to use dynamic geometry software (see Table 10).

Three months after the workshop, we managed to contact $18(82 \%)$ of the 22 teachers. From the questionnaire it was clear that 14 teachers indicated that they intended to use dynamic geometry software in their classrooms to develop concepts in the context of transformations, functions, or geometry (see Table 10). The four teachers with an average score of less than 4 on the Likert scale (for behavior intention) did not use dynamic geometry software in the end. Only 3 of the 14 teachers who had intended to use dynamic geometry software had not used it. 
Table 10: Behavioural intention and actual use $(\mathrm{N}=18)$

\begin{tabular}{|l|c|c|}
\hline \multicolumn{1}{|c|}{ Teaching style } & $\begin{array}{c}\text { Average score for } \\
\text { behaviour intention }\end{array}$ & $\begin{array}{c}\text { Actual use of dynamic } \\
\text { geometry software }\end{array}$ \\
\hline Traditional & 2.3 (no) & no \\
\hline Constructivist & 2.7 (no) & no \\
\hline Traditional & 2.7 (no) & no \\
\hline Constructivist & 3.0 (no) & no \\
\hline Constructivist & 40 (yes) & yes \\
\hline Constructivist & 4.3 (yes) & yes \\
\hline Constructivist & 6.0 (yes) & yes \\
\hline Constructivist & 6.0 (yes) & yes \\
\hline Traditional & 6.0 (yes) & no \\
\hline Constructivist & 6.3 (yes) & yes \\
\hline Constructivist & 6.3 (yes) & yes \\
\hline Traditional & 6.7 (yes) & no \\
\hline Traditional & 7.0 (yes) & no \\
\hline Constructivist & 7.0 (yes) & yes \\
\hline Constructivist & 7.0 (yes) & yes \\
\hline Constructivist & 7.0 (yes) & yes \\
\hline Constructivist & 7.0 (yes) & yes \\
\hline Constructivist & 7.0 (yes) & yes \\
\hline
\end{tabular}

\section{Discussion}

The TPB proposes that people's belief based factors (behavioural beliefs, normative beliefs and control beliefs) have an effect on their behaviour intention and can be correlated with their actual behaviour. This study found that, in the context of these teachers' use of dynamic geometry software in their classrooms, the subjective norm that forms part of the normative beliefs did not make a significant difference. However, predictor variables for attitude towards behaviour and perceived behavioural control might shed light on these grade 10 to 12 mathematics teachers' intention to use dynamic geometry software in their classrooms. The actual use of dynamic geometry software in the classroom of these teachers was determined by the perceived usefulness (PU) of the technology and the general technology proficiency (GTP) of the teachers. These two factors combined will determine the behavioural intention. A positive correlation between general technology proficiency (GTP) and perceived ease of use (PEOU) was expected, however the correlation found was -0.195 . A possible explanation maybe that dynamic geometry software requires completely different skills from what we will describe as general technology proficiency (see Appendix 1).

These results suggest a simplification of the original model in Figure 1. From the regression and the correlation analyses, it emerged that these teachers based their decision on whether to use dynamic geometry software or not on their belief about the perceived usefulness of using dynamic geometry software in relation to their existing teaching practices (see Figure 4).

The suggested Simplified Model (see Figure 4) sufficiently explains the use of dynamic geometry software in $15(83.3 \%)$ of the 18 teachers classrooms. The fact that 3 of the 14 teachers who intended to use dynamic geometry software did not use it was contradictory to the projection of the TBP. But according to Ertmer (2005), additional barriers related to teachers' pedagogical beliefs may be at work. In investigating possible reasons for why they did not in the end use dynamic geometry software in 
their classroom, we interviewed the teachers. In contrast with the other teachers' constructivist approach, these three teachers revealed a more traditional teaching style (see Table 10). This emerged from their responses to the question: "Describe the most effective way to teach mathematics".

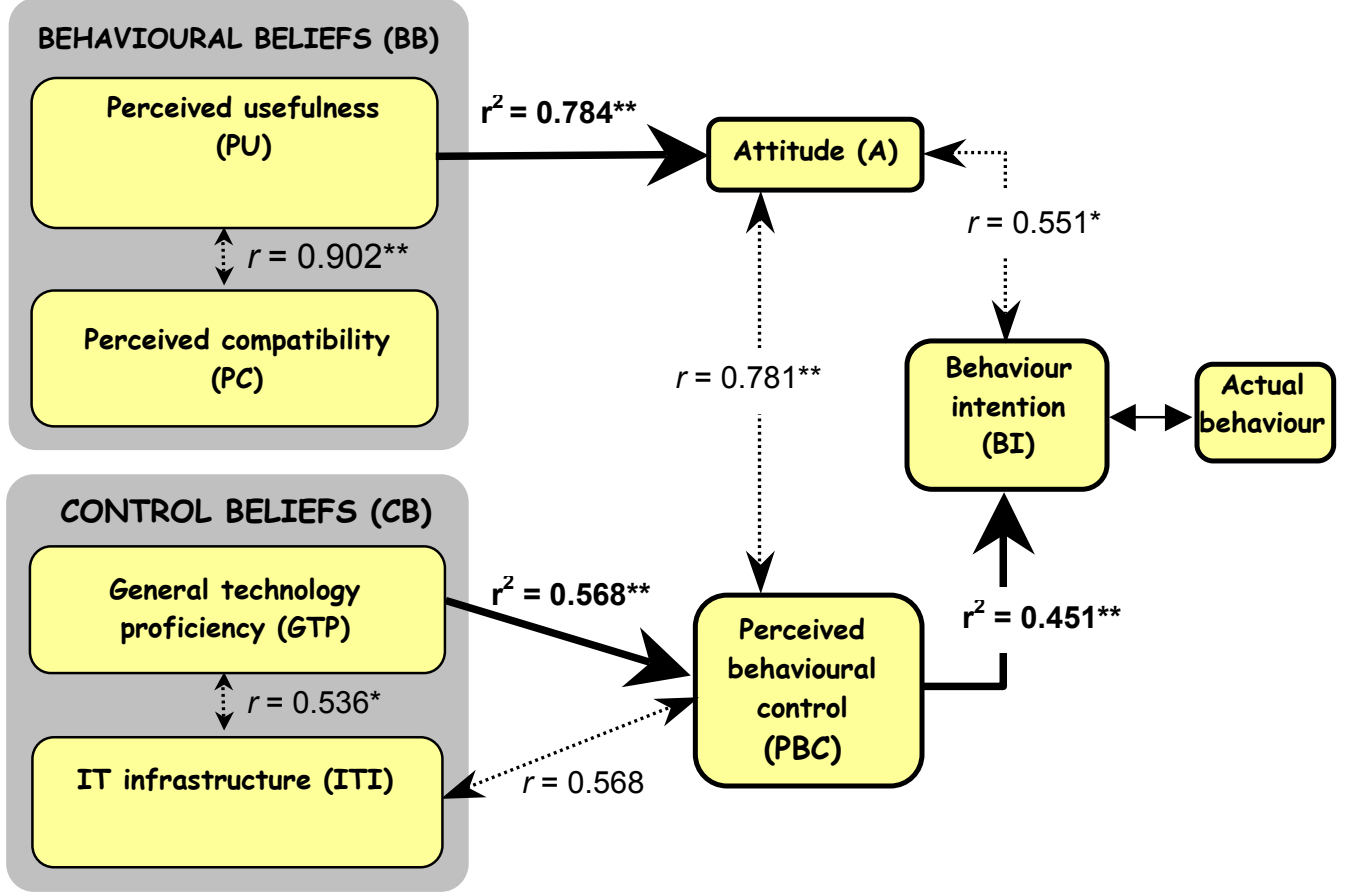

Figure 4: Simplified model for dynamic software

(the dotted line indicates the Pearson correlation coefficient)

These teachers believe that the most effective way to teach mathematics is to "be patient, repeat, and drill", "explain, explore, and give lots of exercises", and "explain and drill". Unlike those of the other teachers who are using dynamic geometry software, these responses represent a more traditional approach, while the use of dynamic geometry software, in general, promotes a more constructivist approach. This suggests that a relationship exists between pedagogical beliefs and technological use. We repeat here the statement by Ertmer (2005), whose study confirmed the importance of these findings: "If we truly hope to increase teachers' uses of technology, especially uses that increase student learning, we must consider how teachers' current classroom practices are rooted in, and mediated by, existing pedagogical beliefs." We can therefore conclude that the teaching style of the three teachers who intended to use dynamic geometry software but did not use it was not compatible with the use of dynamic geometry software.

\section{Conclusion}

The first aim was to examine the influence of mathematics teachers' behavioural beliefs, normative beliefs and control beliefs on their attitudes, subjective norm, and perceived behaviour control respectively. This exploratory study found that these 
teachers' normative beliefs had no significant influence on their subjective norms. However, their beliefs about perceived usefulness of the use of dynamic geometry software to develop concepts on transformations, functions, or geometry determine their attitude and their general technology proficiency influences their perceived behaviour control.

The second objective of the study was to determine the impact of teachers' attitudes, subjective norm, and perceived behaviour control on their intention of using dynamic geometry software in their classrooms to develop concepts in the context of transformations, functions, or geometry. Although this study found a positive significant correlation between attitudes and behaviour intention, only perceived behavioral control, in terms of general technology proficiency, signifcantly determines their behaviour intention.

Finally these teachers' actual behaviour is influenced by the perceived usefulness of the technology or its ability to make their life in the classroom easier. However, if teachers do not have the general technology proficiency to use it in the classroom, it will not be used. A way to improve teachers' use of dynamic geometry software in their classrooms is therefore, firstly, to ensure that the teachers possess general computer proficiency and, secondly, to let them experience the advantage of using the software. In line with our findings, Ertmer (2005) proposes that when considering ways to change teachers' practice, particularly regarding the use of technology, you have to take teachers' pedagogical beliefs into account. He proposes that you introduce teachers to the types of technology use that could support their immediate needs (Ertmer, 2005) in order to increase teachers' confidence in using technology.

These preliminary findings will be able to focus the attention of district officials on what aspects they will have to consider if they want teachers to use dynamic geometry software in their classrooms. This exploratory study yielded important preliminary data and will be used in the design of a full scale study. Further investigations should focus on how and for what purpose teachers used dynamic geometry software in their classrooms.

\section{Acknowledgments}

Funding for this research was provided by the National Research Foundation of South Africa. We would like to thank the teachers of the Tshwane North and South District for their participation and contributions.

\section{References}

Ajzen, I. \& Madden, T. J. (1986). Prediction of goal-directed behavior: attitudes, intentions, and perceived behavioral control. Journal of Experimental Social Psychology, 22, 453-474.

Ajzen, I. (1991). The theory of planned behaviour. Organizational Behavior and Human Decision Processes, 50(2), 179-211.

Ajzen, I. (2006). Theory of Planned Behavior Diagram. http:/ / www.people.umass.edu/aizen/tpb.diag.html

Albion, P. R. (2001). Some factors in the development of self-efficacy beliefs for computer use among teacher education students. Journal of Technology and Teacher Education, 9(3), 321-347. 
Bransford, J. D., Brown, A. L. \& Cocking, R. R. (2000). How people learn: Brain, mind, experience, and school. Washington, DC: National Academy Press.

http: / / www.nap.edu/openbook.php?record_id=6160

Bruce, B. \& Levin, J. (2001). Roles for new technologies in language arts: inquiry, communication, construction, and expression. In J. Jenson, J. Flood, D. Lapp \& J. Squire (Eds), The handbook for research on teaching the language arts. (pp. 536-541). New York: Macmillan.

Clements, D. H., Sarama, J., Yelland, N. J. \& Glass, B. (2008). Learning and teaching geometry with computers in the elementary and middle school. In M. K. Heid \& G. W. Blume (Eds), Research on technology and the teaching and learning of mathematics: Volume 1, Research syntheses (pp. 109-154). New York: Information Age Publishing.

Connell, M. L. (1998). Technology in the constructivist mathematics classroom. Journal of Computers in Mathematics and Science Teaching, 17(4), 311-338.

Cuban, L. (2001). Oversold and underused: Computers in the classroom. London: Harvard University Press.

Davis, F. D. (1989). Perceived usefulness, perceived ease of use, and user acceptance of information technology. MIS Quarterly, 13(3), 319-340.

Debuse, J. C. W., Lawley, M. \& Shibl, R. (2008). Educators' perceptions of automated feedback systems. Australasian Journal of Educational Technology, 24(4), 374-386. http: / / www.ascilite.org.au/ajet/ajet24/debuse.html

Dede, C. (2000). Emerging influences of information technology on school curriculum. Journal of Curriculum Studies, 32(2), 281-303.

Ertmer, P. A. (2005). Teacher pedagogical beliefs: The final frontier in our quest for technology integration? Educational Technology Research \& Development, 53(4), 25-39.

Fishbein, M. \& Ajzen, I. (1975). Belief, attitude, intention, and behavior: An introduction to theory and research. Reading, MA: Addison-Wesley.

Francis, J. J., Eccles, M. P., Johnston, M., Walker, A., Grimshaw, J., Foy, R., Kaner, E. F. S, Smith, L. \& Bonetti, D. (2004). Constructing questionnaires based on the Theory of Planned Behaviour: A manual for health services researchers. [accessed 30 Sep 2009 at http: / / people.umass.edu/ .../Francis\%20etal.TPB $\% 20$ research\%20manual.pdf, verified 20 Feb 2011 at http: / / www.rebeqi.org/ViewFile.aspx?itemID=212]

Garofalo, J., Drier, H., Harper, S., Timmerman, M. A. \& Shockey, T. (2000). Promoting appropriate uses of technology in mathematics teacher preparation. Contemporary Issues in Technology and Teacher Education, 1(1), 66-88.

http: / / www.citejournal.org/vol1 / iss1/ currentissues/mathematics/article1.htm

Hew, K. F. \& Brush, T. (2007). Integrating technology into K-12 teaching and learning: Current knowledge gaps and recommendations for future research. Educational Technology Research $\mathcal{E}$ Development, 55(3), 223-252. [verified 20 Feb 2011] http:/ / courses.ischool.berkeley.edu/i290pm4e/f10/ files/Hew-Brush.pdf

Hu, P. J., Clark, T. H. \& Ma, W. W. (2003). Examining technology acceptance by school teachers: A longitudinal study. Information Management, 41(2), 227-241.

Marcinkiewicz, H. R. (1994). Computers and teachers: Factors influencing computer use in the classroom. Journal of Research on Computing in Education, 26(2), 220-237.

McCabe, P. T. (2004). Contemporary ergonomics. Warrington: CRC Press.

Moore, G. C. \& Benbasat, I. (1991). Development of an instrument to measure perceptions of adopting an information technology innovation. Information Systems Research, 2(3), 192-222. 
Munby, H. A. (1984). A qualitative approach to the study of a teacher's beliefs. Journal of Research in Science Teaching, 21, 27-38.

Rivera Green, I. F. (2005). The emancipatory potential of a new information system and its effect on technology acceptance. Unpublished Master's dissertation. Pretoria: University of Pretoria. [verified 20 Feb 2011] http: / / upetd.up.ac.za/thesis/available/ etd-02132007-140247 /

Rogers, E. M. (2003). Diffusion of innovations, 5th ed. New York, NY: Free Press.

Roschelle, J. M., Pea, R. D., Hoadley, C. M., Gordin, D. N. \& Means, B. M. (2000). Changing how and what children learn in school with computer-based technologies. The Future of Children, Fall/Winter 2000.

Sanders, C. V. (1998). Geometric constructions: visualizing and understanding geometry. Mathematics Teacher, 91(7), 554-556.

Sheppard, B. H., Hartwick, J. \& Warsaw, P. R. (1988). The theory of reasoned action: A metaanalysis of past research with recommendation for modifications and future research. Journal of Consumer Research, 15, 325-343.

Teo, T. (2008). Pre-service teachers' attitudes towards computer use: A Singapore survey. Australasian Journal of Educational Technology, 24(4), 413-424. http: / / www.ascilite.org.au/ajet/ajet24/teo.html

Thang, S. M., Murugaiah, P., Lee, K. W., Azman, H., Tan, L. Y. \& Lee, Y. S. (2010). Grappling with technology: A case of supporting Malaysian Smart School teachers' professional development. Australasian Journal of Educational Technology, 26(3), 400-416. http: / / www.ascilite.org.au/ajet/ajet26/thang.html

Venkatesh, V. \& Davis, F. D. (2000). A theoretical extension of the technology acceptance model: Four longitudinal field studies. Management Science, 46(2), 186-204.

Venkatesh, V., Morris, M. G., Davis, G. B. \& Davis, F. D. (2003). User acceptance of information technology: Toward a unified view. MIS Quarterly, 27(3), 425-478

Vrasidas, C. \& Glass, G. V. (2005). Preparing teachers to teach with technology: Current perspectives on applied information technologies. Greenwich, Conn.: Information Age.

Zhao, Y. \& Cziko, G.A. (2001). Teacher adoption of technology: A perceptual control theory perspective. Journal of Technology and Teacher Education, 9(1), 5-30.

\section{Appendix 1: Questionnaire}

See http: / / www.ascilite.org.au/ajet/ajet27/ stols-appendix1.pdf

\section{Dr Gerrit Stols}

Department of Science, Mathematics and Technology Education, Faculty of Education (Groenkloof Campus), University of Pretoria, Pretoria, South Africa

Email: gerrit.stols@up.ac.za

Professor Jeanne Kriek

Institute for Science and Technology Education

University of South Africa, Pretoria, South Africa

Email: kriekj@unisa.ac.za

Please cite as: Stols, G. \& Kriek, J. (2011). Why don't all maths teachers use dynamic geometry software in their classrooms? Australasian Journal of Educational Technology, 27(1), 137-151. http: / / www.ascilite.org.au/ajet/ajet27/ stols.html 